Supplement of

\title{
Vertical characteristics of aerosol hygroscopicity and impacts on optical properties over the North China Plain during winter
}

Quan Liu, Dantong Liu, Qian Gao, Ping Tian, Fei Wang, Delong Zhao, Kai Bi, Yangzhou Wu, Shuo

Ding, Kang Hu, Jiale Zhang, Deping Ding, Chunsheng Zhao

Corresponding author: Dantong Liu (dantongliu@zju.edu.cn) 


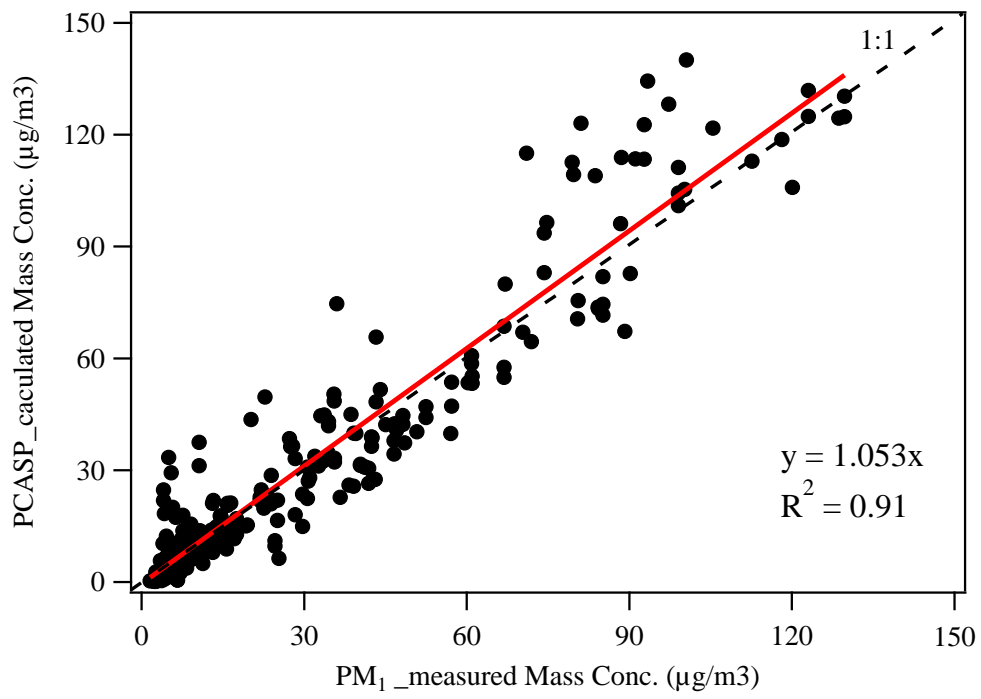

Figure S1. Comparison between PM1 derived from the PCASP size distribution and measurements in the cabin for all flights. 
(a) $1 \mathrm{RH} \_l p$ PBL $\left(53.3 \mu \mathrm{g} / \mathrm{m}^{3}\right)$

$6 \%$

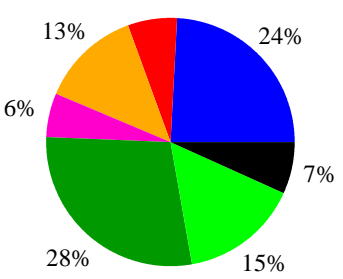

(c) 1RH_p PBL $\left(112.6 \mu \mathrm{g} / \mathrm{m}^{3}\right)$

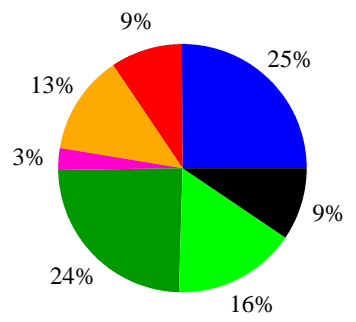

(e) hRH PBL $\left(97.2 \mu \mathrm{g} / \mathrm{m}^{3}\right)$

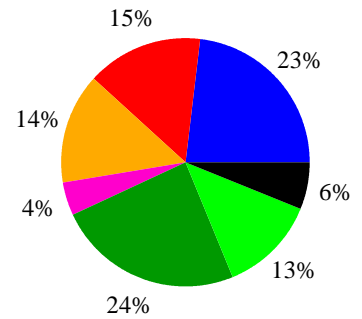

(b) 1RH_lp FT $\left(15.0 \mu \mathrm{g} / \mathrm{m}^{3}\right)$

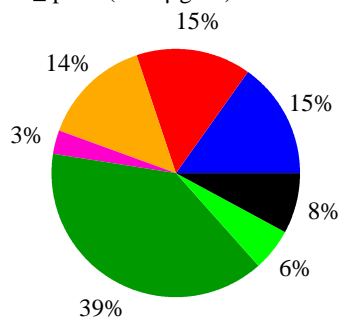

(d) 1RH_p FT $\left(20.6 \mu \mathrm{g} / \mathrm{m}^{3}\right)$

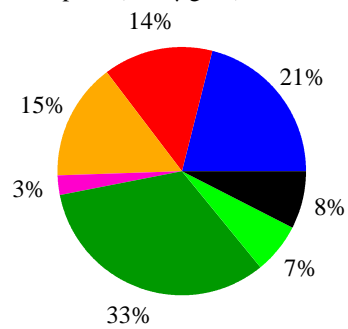

(f) hRH FT $\left(25.3 \mu \mathrm{g} / \mathrm{m}^{3}\right)$

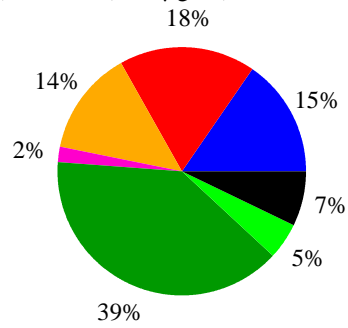

Figure S2. The aerosol chemical compositions in the PBL and FT under all conditions: (a-b) in the PBL and FT under 1RH and less polluted conditions (1RH_lp), (c-d) in the PBL and FT under IRH and polluted conditions (IRH_p), and (e-f) in the PBL and FT under hRH conditions. 

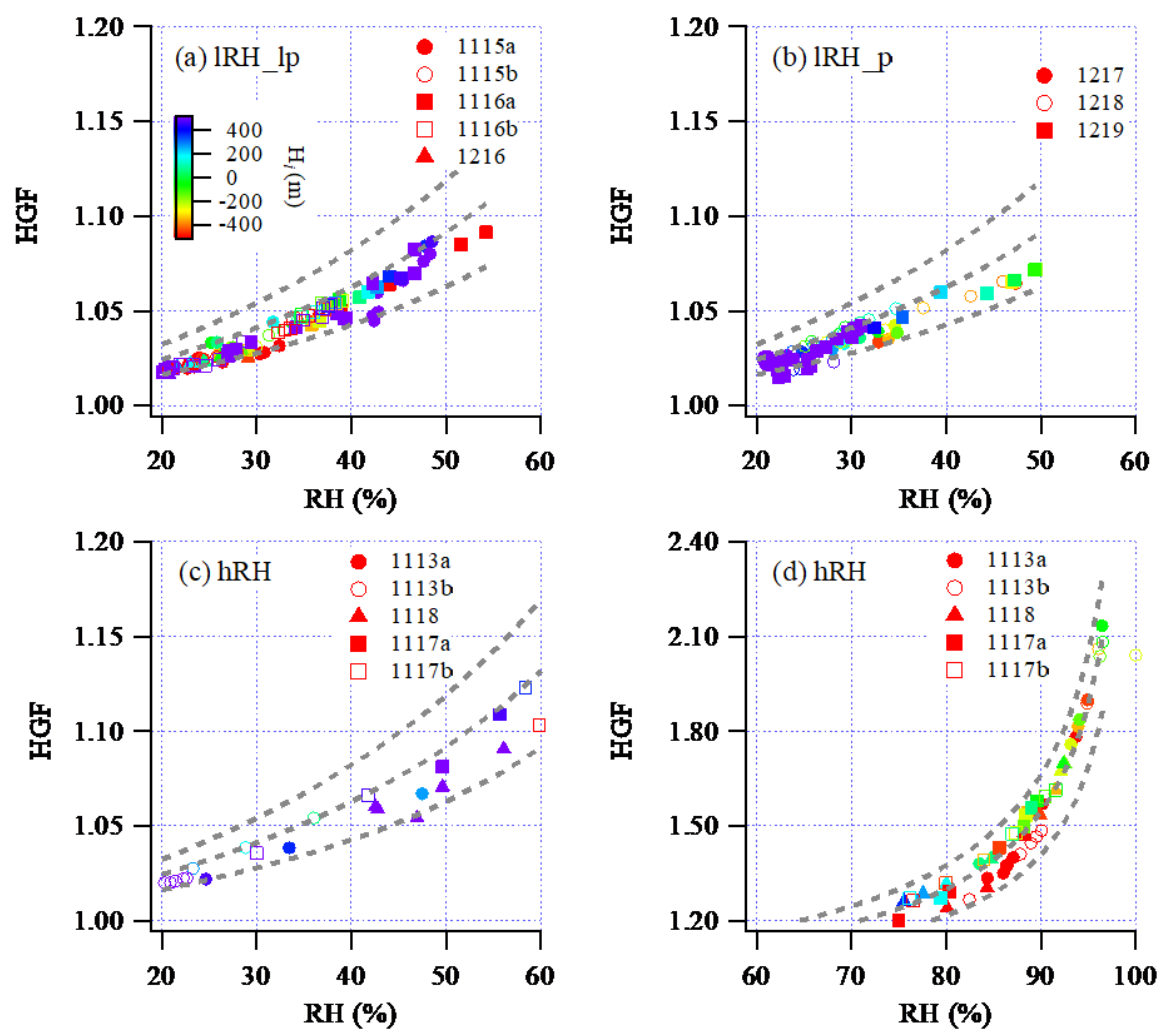

Figure S3. Correlations between hygroscopic growth factor (HGF) and RH, (a) under IRH_lp condition, (b) under IRH_p condition, (c) under $\mathrm{hRH}$ condition, $\mathrm{RH}<60 \%$, and (d) under $\mathrm{hRH}$ condition, $\mathrm{RH}>60 \%$. The reference grey dash lines denote the calculated HGFs by assuming constant $\kappa$ of $0.2,0.3,0.4$, respectively. 

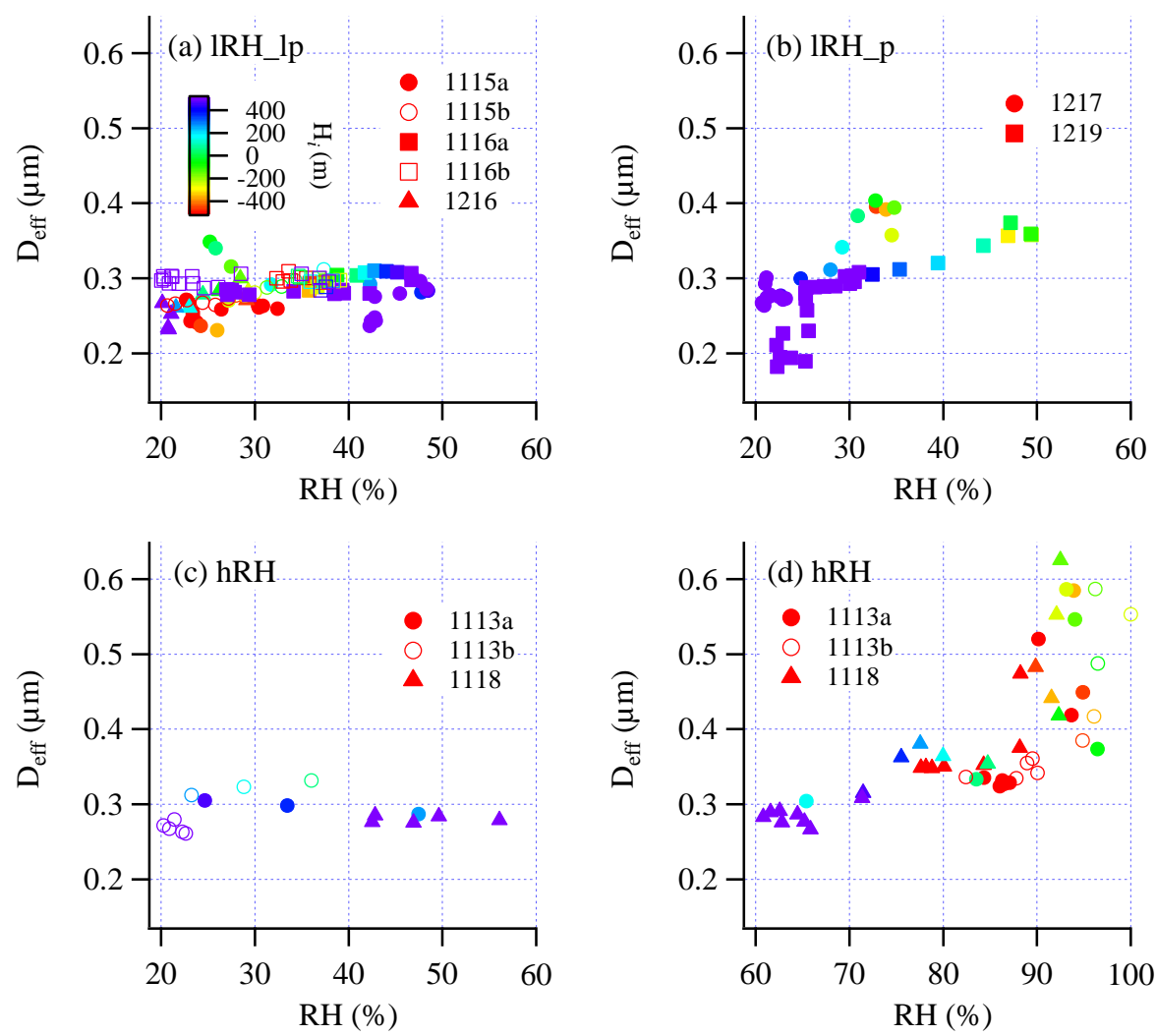

Figure S4. Correlations between Deff and RH for all flights, (a) under 1RH_lp condition, (b) under 1RH_p condition, (c) under hRH condition, $\mathrm{RH}<60 \%$, and (d) under $\mathrm{hRH}$ condition, $\mathrm{RH}>60 \%$. 

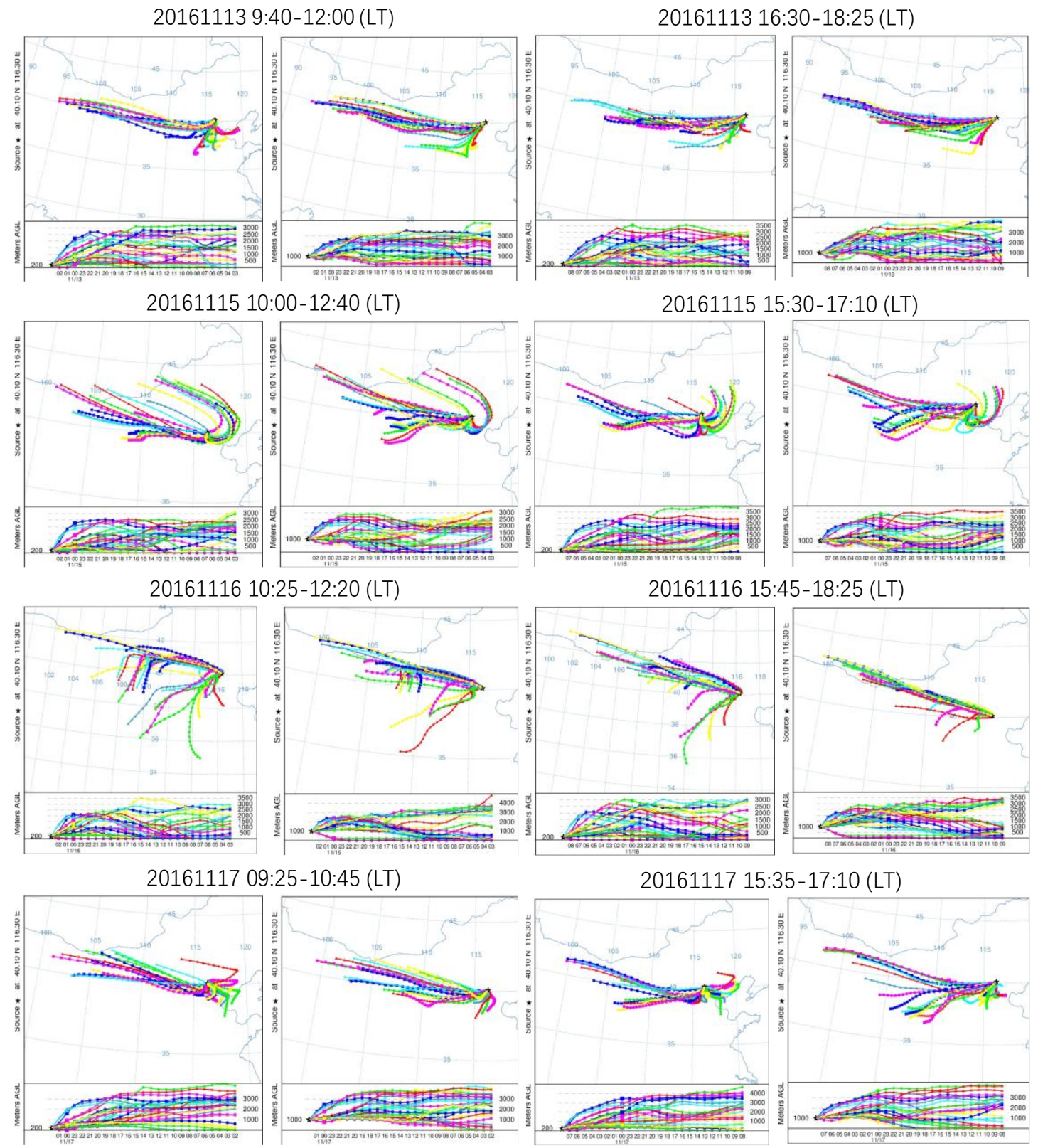

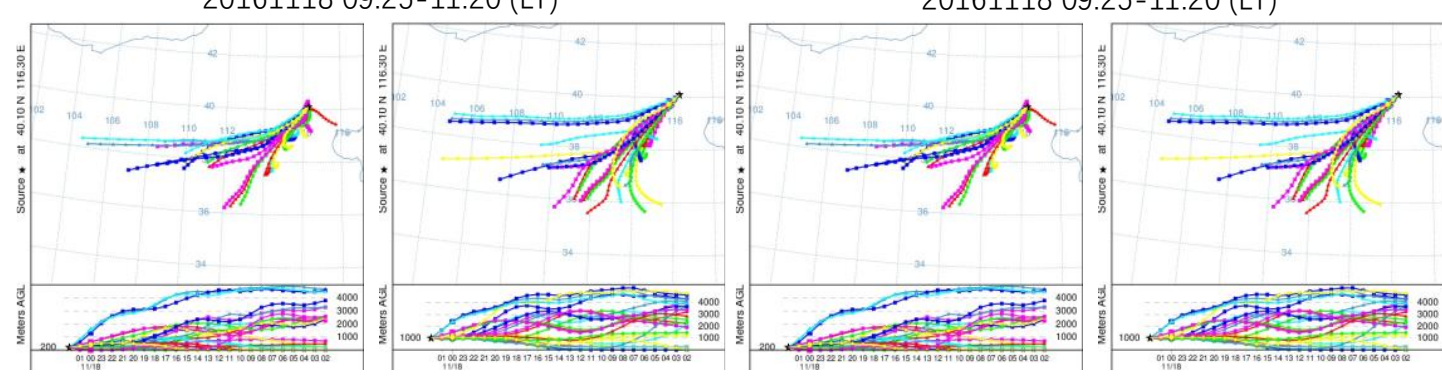

20161217 12:40-16:10 (LT)

20161218 12:10-14:30 (LT)
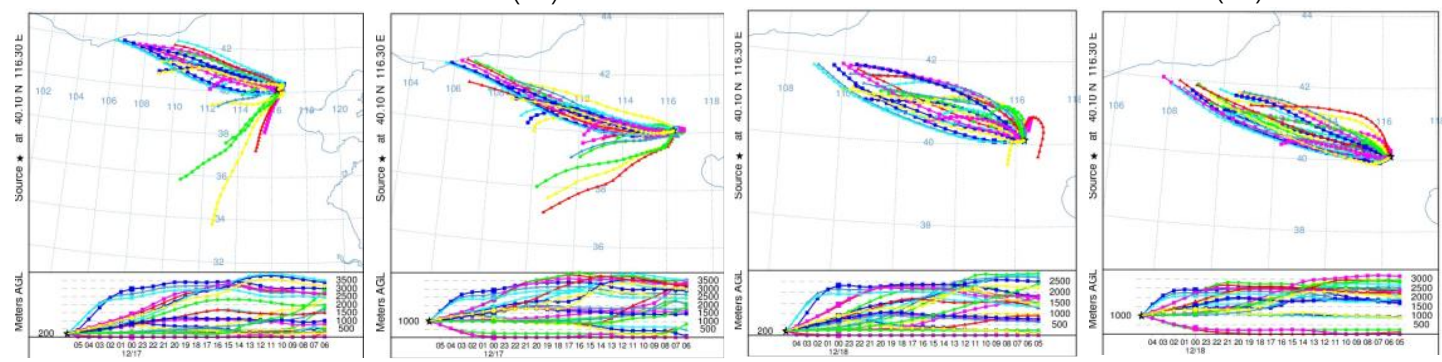

20161219 12:25-16:20 (LT)

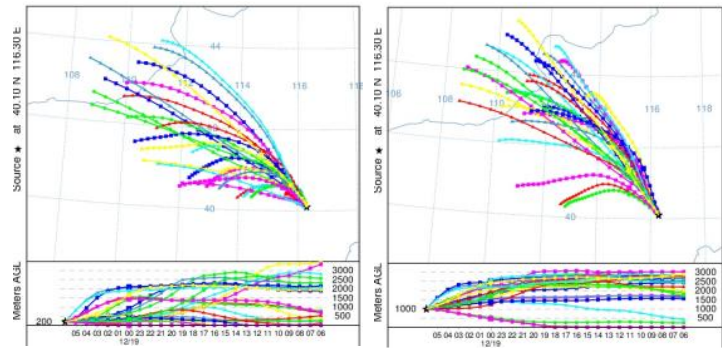

Figure S5. HYSPLIT ensemble backward trajectories during the experiment. The endpoint heights of back trajectories are set to $200 \mathrm{~m}$ a.s.l (left panels) and $1000 \mathrm{~m}$ a.s.l. (right panels). LT=local Time. 